\title{
Lateral medullary syndrome with Ondine's curse.
}

\author{
Yun Wang, Qian Dong, Shujuan Li, Wenli Hu* \\ Department of Neurology, Beijing Chaoyang Hospital, Capital Medical University, Beijing, PR China
}

\begin{abstract}
Objectives: To analyse the clinical characteristic of Lateral Medullary Syndrome (LMS) with Ondine's curse.

Materials and methods: This is a report of 3 cases of LMS with Ondine's curse. Characteristics and clinical presentations of three patients were described and analysed.

Results: All patients were male and they were 63,65 and 84 y old respectively. All had diabetes mellitus and poor glucose control. Patients 2 and 3 had snoring, smoking and alcohol use history. Patients 1 and 2 had hypertension. Ondine's curse occurred on the $5^{\text {th }}, 1^{\text {th }}$ and $23^{\text {rd }} \mathrm{d}$ after their strokes. All were on mechanical ventilation. Patients 2 and 3 were extubated successfully after 4 and $52 \mathrm{~d}$ of onset of Ondine's curse. Patient 1 died.

Conclusions: Ondine's curse is a rare and fatal condition. Diagnosing early, providing life support quickly and improving the variable risk factors are necessary for improving outcome. More researches are needed to elucidate its epidemiology, etiology, clinical characteristic, treatment and prognosis.
\end{abstract}

Keywords: Lateral medullary syndrome, Ondine's curse, Automatic respiration, Clinical characteristic, Risk factor. Accepted on February 12, 2018

\section{Introduction}

Normal human respiratory functions can be categorized into voluntary, automatic, limbic, and reflex respirations [1]. Automatic respiration mainly regulates breathing in response to the changes in oxygen, carbon dioxide and $\mathrm{pH}$ contents in the blood and cerebrospinal fluid [2]. When hypoventilation occurs, the automatic respiration system will regulate the depth and frequency of breaths, even during awake in order to improve hypoxia and hypercapnia. Automatic respiration centers are known located in medulla [1].

Ondine's curse, also known as Central Alveolar Hypoventilation (CAH) syndrome is a rare clinical condition characterized by the loss of automatic respiratory drive, mostly during sleep but also during wakefulness. Two types have been described: congenital and acquired $\mathrm{CAH}$. The congenital $\mathrm{CAH}$ occurs at birth and is extremely rare [3] while the acquired $\mathrm{CAH}$ can result from medulla ischemia, hemorrhage, tumor, infection, demyelinating diseases, trauma, some mitochondrial diseases, degenerative diseases or anoxic-ischemic damage $[2,4]$.

From January 2012 to January 2017, 5011 patients with cerebral infarctions were hospitalized at our institution. Among them, three patients had Lateral Medullary Syndrome (LMS) with Ondine's curse. All progressed to respiratory failure during sleeping. We report these three cases to analyse the clinical characteristic of LMS with Ondine's curse. This report was approved by the Ethics Committee of Beijing Chaoyang Hospital.

\section{Cases}

Case 1, an 84-year-old man with history of hypertension, diabetes mellitus and hyperlipidemia presented with suddenonset vertigo, mild weakness of his left arm and leg, and numbness of left face ten days before admission. No history of snoring, smoking and alcoholism. No positive family history. On admission, his Blood Pressure (BP) was 163/74 mmHg, and the neurologic examination revealed dysarthria, left facial and right body hemianesthesia, and positive bilateral Babinski sign. His Fasting Blood-Glucose (FBG) was $17.30 \mathrm{mmol} / \mathrm{L}$, Low Density Lipoprotein (LDL) was $3.36 \mathrm{mmol} / \mathrm{L}$, glycosylated hemoglobin (HbAlc) was 9.8\%, and Homocysteine (HCY) was $21 \mu \mathrm{mol} / \mathrm{L}$. Electrocardiograph (ECG) and chest X-ray were unremarkable. Brain MRI showed acute infarction in the left lateral medulla (Figure 1a). MR angiography showed mild-moderate stenosis of left Anterior Cerebral Artery (ACA) and right Middle Cerebral Artery (MCA), and the other arteries were normal. On the $13^{\text {th }} \mathrm{d}$ of admission (23 d after onset of stroke), he became apneic during sleep. Emergent intubation and respirator support were initiated. Arterial Blood Gas (ABG) during apnea showed $\mathrm{pH}$ of $6.91, \mathrm{pO}_{2}$ of $81 \mathrm{mmHg}$ and $\mathrm{pCO}_{2}$ of $71 \mathrm{mmHg}$, with an $\mathrm{O}_{2}$ saturation of $84 \%$. Four hours after intubation, his respiration and consciousness did not improve. The respirator therapy was discontinued upon family's request. Then the patient died. 

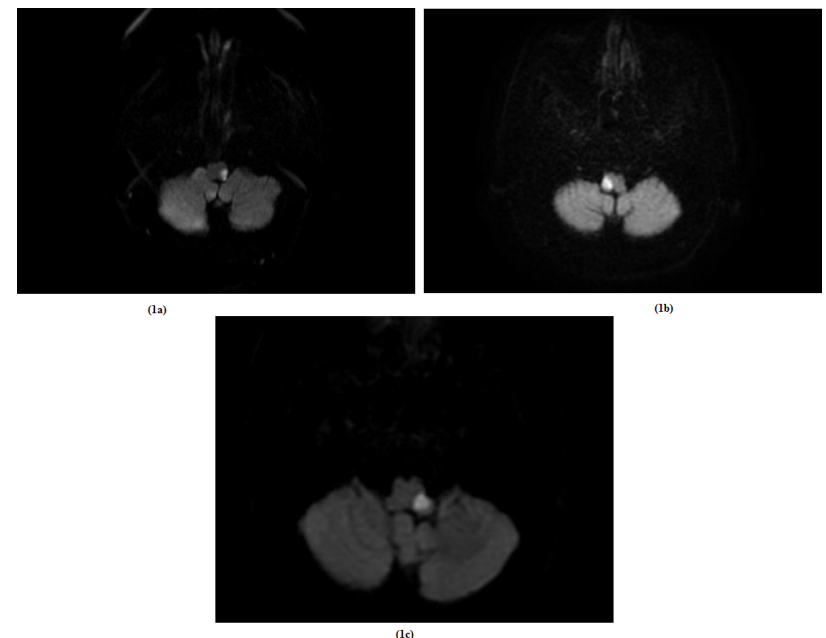

Figure 1. Brain diffusion-weighted imaging of lateral medullary syndrome with Ondine's curse of three patients. 1a: Brain diffusionweighted imaging of patient $1 ; 1 b$ : Brain diffusion-weighted imaging of patient 2; 1c: Brain diffusion-weighted imaging of patient 3.

Case 2, a 63-year-old male patient with smoking, alcoholism, snoring, diabetes mellitus, hyperlipidemia, family history of stroke and a previous stroke 9 years ago, presented to our department complaining of vertigo, dysarthria, dysphagia and headache for $2 \mathrm{~d}$. His father had stroke and no other positive family history. On admission, his BP was $155 / 103 \mathrm{mmHg}$, and the neurologic examination revealed dysarthria, and loss of pharyngeal reflex. His motor and sensory systems were normal. His FBG was $16.27 \mathrm{mmol} / \mathrm{L}$, LDL was $1.08 \mathrm{mmol} / \mathrm{L}$, HbA1c was $11.1 \%$, and HCY was $23 \mu \mathrm{mol} / \mathrm{L}$. ECG and chest X-ray were all unremarkable. Brain MRI showed acute infarction in the right lateral medulla (Figure 1b). In CT angiography, the right Vertebral Artery (VA) wasn't shown, and the other arteries were normal. On the $3^{\text {rd }} \mathrm{d}$ of admission (five days after onset of stroke), he suddenly became apneic during sleep. Intubation and respiratory therapy were given immediately. Initial $\mathrm{ABG}$ showed $\mathrm{pH}$ of 7.21, $\mathrm{pO}_{2}$ of 117 $\mathrm{mmHg}$ and $\mathrm{pCO}_{2}$ of $62 \mathrm{mmHg}, \mathrm{O}_{2}$ saturation at $98 \%$. His consciousness and respiration recovered gradually. After $4 \mathrm{~d}$ ' mechanical ventilation, he was successfully weaned and extubated.

Case 3, a 65-year-old male patient with smoking, alcoholism, snoring, diabetes mellitus and hypertension presented with chief complaint of vertigo, diplopia and dysphagia for $1 \mathrm{~d}$. He also had nausea, vomiting and numbness of his left face and right side of his body. No positive family history. On admission, his BP was $133 / 65 \mathrm{mmHg}$, and the neurologic examination revealed dysarthria, loss of pharyngeal reflex and hemianesthesia of left facial and right body. The motor system was normal. His FBG was $21.16 \mathrm{mmol} / \mathrm{L}$, LDL was 2.40 $\mathrm{mmol} / \mathrm{L}, \mathrm{HbAlc}$ was $9.6 \%$, and $\mathrm{HCY}$ was $23 \mu \mathrm{mol} / \mathrm{L}$. ECG and chest X-ray were all unremarkable. Brain MRI showed acute infarction in the left dorsal-lateral medulla (Figure 1c). CT angiography was negative except mild stenosis of left internal carotid. On the $9^{\text {th }} \mathrm{d}$ of admission (ten days after onset of stroke), he became apneic during sleep suddenly. Intubation and respirator support were initiated. His $\mathrm{ABG}$ showed $\mathrm{pH}$ of 7.1, $\mathrm{pO}_{2}$ of $118 \mathrm{mmHg}$ and $\mathrm{pCO}_{2}$ of $57 \mathrm{mmHg}$, and $\mathrm{O}_{2}$ saturation at $100 \%$. He survived but his consciousness did not improve. After $52 \mathrm{~d}$ of ventilator support, this patient was weaned and extubated successfully.

\section{Discussion}

In all our 3 patients, the apnea happened during sleep and their initial ABGs showed high $\mathrm{PaCO}_{2}$ (Table 1). The diagnosis of Ondine's curse was therefore made.

Table 1. Clinical material of LMS patients.

\begin{tabular}{|c|c|c|c|c|c|c|c|c|c|c|}
\hline \multirow[t]{2}{*}{ Case } & \multirow[t]{2}{*}{ Age } & \multirow{2}{*}{$\begin{array}{l}\text { Onset time } \\
\text { stroke (d) }\end{array}$} & \multirow{2}{*}{ since } & \multirow[t]{2}{*}{ Risk factor } & & \multirow[t]{2}{*}{ FBG (mmol/L) } & \multirow[t]{2}{*}{ HbA1c (\%) } & \multicolumn{2}{|c|}{ Blood gas analysis } & \multirow{2}{*}{$\begin{array}{l}\text { Time of wean off } \\
\text { (d) }\end{array}$} \\
\hline & & & & & & & & $\mathrm{pH}$ & $\mathrm{pCO}_{2}(\mathrm{mmHg})$ & \\
\hline 1 & 84 & 23 & & $\begin{array}{l}\text { Diabetes } \\
\text { hypertension }\end{array}$ & mellitus, & 17.3 & 9.8 & 6.91 & 71 & died \\
\hline 2 & 63 & 5 & & $\begin{array}{l}\text { Diabetes mellitus, } \\
\text { alcoholism, snoring }\end{array}$ & smoking, & 16.27 & 11.1 & 7.21 & 62 & 4 \\
\hline 3 & 65 & 10 & & $\begin{array}{l}\text { Diabetes } \\
\text { hypertension, } \\
\text { alcoholism, snoring }\end{array}$ & $\begin{array}{l}\text { mellitus, } \\
\text { smoking, }\end{array}$ & 21.16 & 9.6 & 7.1 & 57 & 52 \\
\hline
\end{tabular}

Respiration is centrally controlled by 3 groups of neurons: 1) the pontine respiratory group, which controls switching between inspiration and expiration, consists of the parabrachial/Kolliker-Fuse complex in the rostral dorsolateral pons; 2) the dorsal respiratory group, which receives afferent signals from peripheral respiratory chemoreceptors and pulmonary mechanoreceptors and transmits to the brainstem respiratory network, is located in the nucleus solitarius; 3) the Ventral Respiratory Group (VRG), which contains inspiration, expiration and respiratory rhythm-generating neurons, is a respiratory column extending from cervical cord $\mathrm{C} 1$ to the level just below the facial nucleus [2,5]. The infarction of medulla oblongata can cause the impairment of VRG and involve the automatic respiration system. In patients with LMS, the feedback mechanisms of automatic respiration system, which dependent on changes in oxygen, carbon dioxide, and $\mathrm{pH}$ in the blood and CSF, will be hyporeactive [2], so they could have difficulty to regulate the respiration when 
hypoxia and hypercapnia happened. Bilateral lesions are not necessary to cause Ondine's curse [2]. Unilateral medullary lesion can cause the automatic respiration dysfunction because the efferent fibers from the respiratory centers descend on both sides of the spinal cord after crossing at the medullary level. Hence, a unilateral lesion can affect the efferent pathways on both sides [1], and develop Ondine's curse.

The sudden apnea during sleep may be caused by clinical worsening by thrombi propagation, reduced blood flow in the ischemic zone, and perilesional edema [6,7]. Stroke patients with Sleep-Disordered Breathing (SDB) may have potential risk for Ondine's curse as well, because most Ondine's curse occurred in the night-time. More than $50 \%$ of patients with acute stroke have SDB [2]. But Ondine's curse is rare. Its prevalence is unclear. In our department, the morbidity was $0.06 \%$. We consider there may be 3 necessary conditions to trigger Ondine's curse in patients with stroke: 1) infarctions which affected automatic respiration system, 2) apnea, mostly during sleep and 3) other suspected risk factors.

All 3 patients had diabetes and poor glucose control. Diabetes may be a risk factor for Ondine's curse. According to the previous reports, diabetes can increase SDB prevalence [8]. The reason is unclear. Chronic diabetes may affect all organs including respiratory system. It may be caused by microangiopathy of pulmonary capillaries, autonomic neuropathy, myopathy of respiratory muscles or changes in collagen increase the collapsibility of the upper airway [9]. Patients 1 and 2 both had hypertension. According to the previous reports, stroke patients with older age, male gender, night-time stroke onset, higher body mass index, diabetes, hypertension, coronary heart disease, excessive daytime sleepiness (higher Epworth sleepiness score) preceding stroke onset, and macroangiopathic etiology of stroke were more likely to have SDB8. Not all LMS patients would develop Ondine's curse. People with these risk factors may have higher prevalence of Ondine's curse. Thus, improving risk factors is necessary to decrease its incidence.

Ondine's curse is a sudden and fatal condition. Once it occurs, mechanical ventilation is necessary. Only some can successfully wean off the ventilator and survive. Infection is the most common cause of death after mechanical ventilation [10]. Mishina et al. inferred that tracheotomy might be effective to improve the outcome after onset of Ondine's curse due to assisting alveolar ventilation by reducing dead space ventilation [11]. Performing the Polysomnogram (PSG) for LMS patients, especially for those patients with high risks, is quite important for the prevention of Ondine's curse. Early diagnosis and the use of Continuous Positive Airways Pressure (CPAP) can be effective [12]. No drug therapy was proved to be effective. Patients with the risk of Ondine's curse should not be supplied with oxygen without ABG monitoring. Supplying with oxygen may delay the diagnosis and also aggravate hypercapnia due to hypoventilation and hyporeactivity of the breathing center [13].

Ondine's curse may be delayed after the onset of stroke. Our 3 patients had it on the $5^{\text {th }}, 10^{\text {th }}$ and $23^{\text {rd }} \mathrm{d}$ post stroke. It could occur 3 months after the brainstem stroke [14]. The delay in the development of Ondine's curse after LMS may be explained by the secondary neuronal degeneration, apoptosis, or abnormal plasticity involving local synaptic interconnections [2].

\section{Conclusion}

Even rare, Ondine's curse can be secondary to unilateral LMS, especially in the patients with risk factors. Ondine's curse is often fatal. Therefore, diagnosing early and improving the risk factors aggressively are necessary. PSG should be done as soon as possible. Ondine's curse is still not well understood, more researches are needed to define its epidemiology, etiology, clinical characteristics, treatment options and prognosis.

\section{Funding}

This study was funded by a grant from the National Natural Science Foundation of China (No. 81271309) and a grant from the Natural Science Foundation of Beijing Municipality (No. 7122067).

\section{Conflict of Interest}

The authors declare no conflict of interest.

\section{References}

1. Terao S, Miura N, Osano Y. Rapidly progressive fatal respiratory failure (Ondines curse) in the lateral medullary syndrome. J Stroke Cerebrovasc Dis 2004; 13: 41-44.

2. Mendoza M, Latorre JG. Pearls and oysters: reversible Ondines curse in a case of lateral medullary infarction. Neurology 2013; 80: 13-16.

3. Nattie E. Ondine undone. N Engl J Med 2015; 373: 573-575.

4. Schestatsky P, Fernandes LN. Acquired Ondines curse: case report. Arq Neuropsiquiatr 2004; 62: 523-527.

5. Benarroch EE. Brainstem respiratory chemosensitivity: new insights and clinical implications. Neurology 2007; 68: 2140-2143.

6. Caplan LR. Worsening in ischemic stroke patients: is it time for a new strategy? Stroke 2002; 33: 1443-1445.

7. Yamamoto H, Bogousslavsky J, van Melle G. Different predictors of neurological worsening in different causes of stroke. Arch Neurol 1998; 55: 481-486.

8. Bassetti CL, Milanova M, Gugger M. Sleep-disordered breathing and acute ischemic stroke: diagnosis, risk factors, treatment, evolution, and long-term clinical outcome. Stroke 2006; 37: 967-972.

9. Vojtkova J, Ciljakova M, Michnova Z. Chronic complications of diabetes mellitus related to the respiratory system. Pediatr Endocrinol Diabetes Metab 2012; 18: 112-115.

10. Kumral E, Uzunkopru C, Ciftci S. Acute respiratory failure due to unilateral dorsolateral bulbar infarction. Eur Neurol 2011; 66: 70-74. 
11. Mishina M, Ohkubo S, Kamiya N. Efficacy of tracheostomy for central alveolar hypoventilation syndrome caused by lateral medullary infarction. J Nippon Med Sch 2014; 81: 276-284.

12. Brown DL, Chervin RD, Kalbfleisch JD. Sleep apnea treatment after stroke (SATS) trial: is it feasible? J Stroke Cerebrovasc Dis 2013; 22: 1216-1224.

13. Planjar-Prvan M, Krmpotic P, Jergovic I. Central sleep apnea (Ondines curse syndrome) in medullary infarction. Acta Med Croatica 2010; 64: 297-301.

14. Lassman AB, Mayer SA. Paroxysmal apnea and vasomotor instability following medullary infarction. Arch Neurol 2005; 62: 1286-1288.

\section{*Correspondence to}

Wenli $\mathrm{Hu}$

Department of Neurology

Beijing Chaoyang Hospital

PR China 